\title{
Navigating Digital Borderscapes: A Case Study from Rohingya Refugee Settlements in Bangladesh
}

\author{
Faheem Hussain \\ School for the Future of Innovation in Society, \\ Arizona State University, Tempe, Arizona, US \\ Faheem.Hussain@asu.edu \\ Yenn Lee \\ Corresponding author | ORCID: 0000-0002-0708-2948 \\ Doctoral School, soAS University of London, London, UK \\ yl22@soas.ac.uk
}

\begin{abstract}
Based on a case study of the lived experiences of Rohingya refugees in Bangladesh between 2017 and 2019, this article focuses on displaced people's digital needs and innovative efforts to navigate the challenges in their situation. The article first discusses the major barriers faced by Rohingya refugees in using various digital devices and platforms and how these obstacles adversely affect them in obtaining necessary information and humanitarian services. Our findings from the field highlight the uniquely important role that mobile repair shops in the camps play in providing online-offline hybrid solutions to circumvent restrictions imposed on the refugee community by the host government. The findings also show that different types of community leaders have emerged and that Rohingya women use digital means to push back against double discrimination. The article concludes with policy considerations related to the geopolitically transcendent issues of displacement, democracy, and digital rights.
\end{abstract}

\section{Keywords}

borderscapes - bricolage - digital rights - gender - refugees - Rohingyas 


\section{Introduction}

People have always moved around the world in search of better living conditions, but the phrase 'refugee crisis' became cemented in the public discourse around 2015, when high numbers of refugees, mainly from Syria, Iraq, and Afghanistan, fled armed conflict in their countries and arrived in Europe. The European media coverage of the new arrivals showed 'disturbing trends', in the words of Zaborowski and Georgiou (2016), in advocating for stronger border controls against outsiders to protect citizens of countries there.

In addition, the academic literature has also grown significantly in the number of publications on the topic in recent years. For example, a simple search of the terms refugee $A N D$ crisis on the ISI Web of Science/Knowledge (conducted by the authors on 21 August 2020) yields several hundred results for every year since 2015, but a much lower number of results, never more than 45, for each year from 1969 to 2014. The same soaring trend is observed in 2015 for other bibliographic databases and search engines, such as EBSCO and Google Scholar.

Although this growing research attention to the lives of refugees is a welcome development, so far it has centred on the perspectives of European hosts. This article redirects attention to Rohingya Muslims, who fled religious persecution in the Buddhist-majority Myanmar in 2017 and sought asylum in the neighbouring Bangladesh. We are particularly interested in how they access and use digital resources in trying to adapt to the host society.

This case study is important for three reasons. First, it contributes to redressing the Eurocentric imbalance in current refugee studies. Our study concerns refugee (Rohingya) and host (Bangladeshi) populations that have both been underrepresented in the literature. Second, it offers a rare and longterm account of the everyday life of the Rohingya as a 'stateless community' in Bangladesh. The United Nations describes the Rohingya as the 'world's most persecuted minority' and calls for international collaboration to resolve their ongoing peril (Al Jazeera 2018; UNHCR 2019). However, much is yet to be learnt about their lived experiences on the ground, a gap this study is intended to fill. Third, it advances the notion of digital rights. Refugee policies are inseparable from broader discussions on fundamental human rights and freedoms. However, 'digital rights' entered the discussions relatively recently, and despite a growing movement to consider digital rights fundamental human rights (Reventlow \& McCully 2019), in practice, they are not always treated as such, especially in dire life situations. The scepticism and hostile attitudes expressed on social media and in online news comments in 2015 towards Syrian refugees who possessed smartphones are a case in point (Hussain 2018; O'Malley 2015). 
By focusing on the digital aspects of the experience of displacement and resettlement, our study contributes to discussions on the digital rights of people who do not fit neatly within discrete nation-states. To explore this issue, we first consider the historical and geopolitical context of the 2017 exodus of Rohingya refugees to Bangladesh. It then breaks down our central research question and describes the ethnographic fieldwork we conducted between 2017 and 2019. Next, drawing upon literature on the confluence of borders and digital technology, we discuss our findings as well as their implications for policies concerning the Rohingya population and other forcibly displaced groups facing similar challenges.

\section{$2 \quad$ Brief Historical Background}

The history of the Rohingya is marked by exclusion, discrimination, and misrepresentation. Some historians, such as Rüland (2017), date the arrival of Rohingyas in Myanmar (Burma) to the eighth century, seeing them as an integral part of the Burmese population. Others, including Seekins (2017), consider them as having migrated from Bengal (currently in the People's Republic of Bangladesh and the state of West Bengal, India) to Myanmar only after the first Anglo-Burmese war in 1824. Even according to this conservative interpretation, however, Rohingyas' right to Burmese citizenship was constitutionally recognized after Burma's independence from Britain in 1945, and they were given the status of an ethnic minority in the Burmese constitution in 1961 (Mohdin 2017).

Unfortunately, the situation took a turn to the worse for Rohingyas after the 1962 military coup, and in 1982, under the then-new citizenship law, they were stripped of the right to full citizenship, thus becoming stateless in their own country (Parashar \& Alam 2019). For decades, the army-led administrations in Myanmar consistently discriminated against the Rohingya, leaving them with extremely limited access to education, health care, and other basic rights.

Often likened to the erstwhile apartheid regime in South Africa (Amnesty International 2017), this systemic discrimination against the Rohingya eventually culminated in what the media described as 'ethnic cleansing operations' in 2017. According to a 2019 estimate by the United Nations High Commissioner for Refugees (UNHCR), since August 2017, about 800,00o Rohingyas had fled to Bangladesh to escape violent oppression by Myanmar's army and local militias. Before this latest exodus, approximately 400,000 Rohingyas were already based in Bangladesh as undocumented refugees since the 1970s. 
Rohingyas have been deprived of the right to internet and mobile connections, in both Myanmar and Bangladesh. The government in Myanmar strictly prohibited internet access throughout the Rakhine state, the homeland of the Rohingya. After fleeing to Bangladesh, Rohingyas have continued to face similar deprivation. The Bangladesh government has an official policy in which only those with biometric national identification cards are allowed to purchase a SIM card for internet or mobile services. Rohingya refugees do not have these ID cards, and hence they cannot own a Bangladeshi sim legally (see also UNHCR 2O2O).

The government installed a small number of free-of-charge phone booths across the camp areas, but they are hardly used, mostly because of privacy concerns. In reality, refugees buy sIms for mobile devices from local Bangladeshis at higher prices, borrowing the locals' ID cards or using fake ID s. These practices place them in a legally vulnerable position, but their urgent need for information and communication compels them to take the risk.

\section{$4 \quad$ Research Question and Fieldwork}

The question at the centre of this article is how Rohingya refugees meet their digital needs while navigating restrictions imposed by the host government. The article contributes to policy discussions concerning Rohingya refugees by foregrounding their own lived experiences. It is based on ethnographic fieldwork, conducted on multiple trips between November 2017 and December 2019, in the Kutupalong, Balukhali, and Teknaf refugee camps in Bangladesh. Kutupalong, in particular, is known to be the world's largest of its kind, where approximately 6oo,ooo refugees live in an area of no more than 13 square kilometres (UNHCR 2019). The field trips were supported by Arizona State University and drew on close collaboration with reputed development nongovernmental organizations ( $\mathrm{NGOS}$ ) in the region, namely BRAC $^{1}$ and Young Power in Social Action. ${ }^{2}$

Over a period of three years, we spoke with around 400 people on the ground. This includes individual semi-structured interviews with 150 Rohingya refugees and 50 NGO personnel. We also conducted fourteen focus group

1 Accessible at https://www.brac.net (accessed 22 April 2021).
2 Accessible at https://ypsa.org (accessed 22 April 2021). 
discussions, covering various social, political, and cultural issues that our refugee participants encountered in the camps, their aspirations, and innovative local practices born of necessity.

First, in November 2017, the research team visited the camp areas for five days, conducting in-depth interviews with ten Rohingya refugees and twenty NGO workers, as well as a series of focus group discussions with thirty refugees. Equal numbers of men and women were represented.

One immediate finding from this initial round of data collection is that Rohingyas have no political representation in Bangladesh - as was the case in Myanmar - and, consequently, they rely on a traditional, community-based leadership model. Guided by this finding, when we returned to the field in December 2018, we stayed for eight days and expanded our interviews and focus groups to include senior and leadership figures. All our participants at this stage were based in Camps 11 and 12.

Furthermore, our fieldwork in 2017 and 2018 revealed the existence of a 'microecosystem' of digital resources for everyday life in the camps. This motivated us, in 2019, to delve further into the refugee participants' experiences in using digital means for sociality and collective action. We paid special attention to documenting their creative ways of surmounting regulatory and technological barriers in their digitally mediated activities.

That year, the team spent twenty days on the ground. During this period, the locations of data collection were further diversified. Six focus groups were held in Camps 11, 13, and 14, and our interactions expanded to encompass working and homemaking women, men with higher and lower literacy levels, and majhis (community leaders) and other types of local leaders. In addition to conversations with these participants, we also conducted first-hand observations in various spaces that the NGOS ensured were safe for specific groups of refugees (e.g. women, children, and seniors), such as learning centres and health care facilities.

Marketplaces turned out to be another important space in this microecosystem. Our observations led us in particular to mobile repair and recharge shops, which flourished as de facto hubs for social and political activities by camp dwellers. Hence, on our last three visits in 2019, we conducted semi-structured interviews with fifteen people who ran these shops.

Given the politically vulnerable status of the Rohingya community, the sensitive nature of our research topic, and the absence of an official writing system in the Rohingya language, we approached the process of obtaining informed consent from the participants with extreme caution. All our correspondence with the refugees and related personnel were reviewed and approved by the 
Institutional Review Board of Arizona State University. All our interviews and focus group discussions were conducted on a voluntary basis, and we sought a delicate balance between protecting the privacy of the participants and supporting their desire to be seen and heard in their own terms.

\section{Theoretical Framework}

Our ethnographic case study offers contextualized insights into the living conditions of Rohingya refugees in Bangladesh since their 2017 exodus. By doing so, it aims to contribute to improvement in policies concerning the Rohingya population and other forcibly displaced groups faced with similar challenges in other parts of the world.

We draw on two strands of the existing literature. First, our research is informed by the literature on 'borderscapes'. This term is a relatively recent addition to critical border studies, articulated by scholars such as Harbers (2003), Dell'agnese and Szary (2015), Perera (2007), and Rajaram and Grundy-Warr (2007). In brief, combining 'borders' and Appadurai's (1990) notion of 'scapes', i.e. global flows of people, technology, capital, information, and ideologies (Schimanski and Wolfe, 2017: 155), the term conceptualizes borders as something in flux, operating differentially vis-à-vis different groups of people, and creating liminal spaces occupied by competing actors and discourses (Rajaram \& Grundy-Warr 2007). To put it another way, a borderscape is 'a border zone without borders' (Krichker 2019:2) and is continuously created and operated through discourses, performances, and representations (Cassidy et al. 2018). This conceptualization is particularly helpful for us in thinking beyond the official lines of demarcation of national territories and in capturing the ongoing 'bordering' processes within refugee camps.

Second, this study is also informed by a rapidly growing body of literature on how and to what extent digital technology transforms borders and the cross-border movement of people. This transformation is manifested in various ways. Mann and Daly (2020), among others, note that states increasingly work closely with transnational technology companies and expand their control and influence beyond their territorial borders.

With the power balance tipped further towards the states, many human rights NGOS, such as Privacy International (2020), have pointed out that digital information and communication technologies, especially mobile phones, leave refugees more vulnerable than ever to tracking and surveillance by their host governments. Wall, Campbell, and Janbek (2017) examined the ways in which 
Syrian refugees in the Zaatari refugee camp in Jordan use mobile phones to mitigate what the authors call 'information precarity'. In proposing this term, they highlight the ambivalent nature of the situation. The mobile phone is 'as important as water and food' in the camp, as one of their refugee participants put it (ibid.: 253), but having a mobile phone is not synonymous with being able to access relevant information, especially in such unstable environments. In a similar vein, Gillespie et al. (2018) recount the experiences of Syrian and Iraqi refugees who used smartphones during their perilous journey to reach Europe. Gillespie et al. find that refugees' relationships with their smartphones are granular, ambivalent, and contradictory in nature, as the phones are 'at once a lifeline and can pose many risks' (ibid.: 9).

Aricat (2015) observes similar disparities in digital access among economic migrants. Based on in-depth interviews with Indian migrant workers in Singapore, he highlights their lack of say in matters that affect their own lives and raises the importance of providing migrants with more space, both offline and online, to air their opinions (ibid.: 33).

The existing literature offers rich discussions, as outlined above, but it also points to areas that require further research. We are particularly interested in two such areas. First, the literature on the digital experience of refugees so far focuses on either technological barriers that refugees face or technological solutions to the 'refugee crisis' at the national and international levels. However, relatively little attention has been paid to individual refugees' agency and creativity in navigating precarious conditions. Second, people experience borders differently depending on various factors, such as ethnicity, gender, and class, as well as how these factors intersect, but the literature so far focuses on ethnicity.

Below, we present our findings from the field, organized around the themes of community leadership, education and training, and digital constraints and circumvention. The findings highlight Rohingya refugees' resilient efforts at self-organization.

\subsection{The Formation of Newer Leadership}

Years of state-sponsored repression of Rohingyas' formal leadership led to the creation of alternative, informal leadership. We observed that three different groups of leaders emerged in the Rohingya refugee camps: majhis, imams and other religious leaders, and political leaders. 


\subsubsection{Majhis}

The refugee camps are supported by the Bangladesh government and donor agencies, but day-to-day life in the camps is ultimately organized under the direction of community leaders known as majhis. They are not elected but, rather, are promoted by clusters of people occupying different areas, with each cluster comprising from 50 to 250 families. The majhi system has a clear hierarchy, with a head majhi leading a cadre of other majhis in a given area. Almost all the majhis are men, with very few exceptions.

Majhis are de facto representatives of the Rohingya community before the host government, which, in return, provides them with nominal monetary incentives. Majhis are also responsible for creating and managing the lists of Rohingyas eligible for different types of humanitarian support. Holding this significant responsibility has enhanced their social and political influence over the other members of the community.

In the left-hand image in Figure 1, a majhi shares with the research team his pen-and-paper method of keeping records on Rohingyas under his care, because of unaffordability of digital alternatives. ${ }^{3}$ The top-right-hand image shows a typical model of a 'non-smart' mobile phone with a dual-sim feature, popular among camp dwellers. Many Rohingyas have sIM cards from both Myanmar and Bangladesh and switch between the two based on the available mobile signals in the border areas. The bottom-right-hand image displays the public service announcement (PSA) system at a makeshift mosque. Rohingya refugees consider PSAs from their mosques as one of the most reliable sources of information. The most commonly communicated message is about missing and found children.
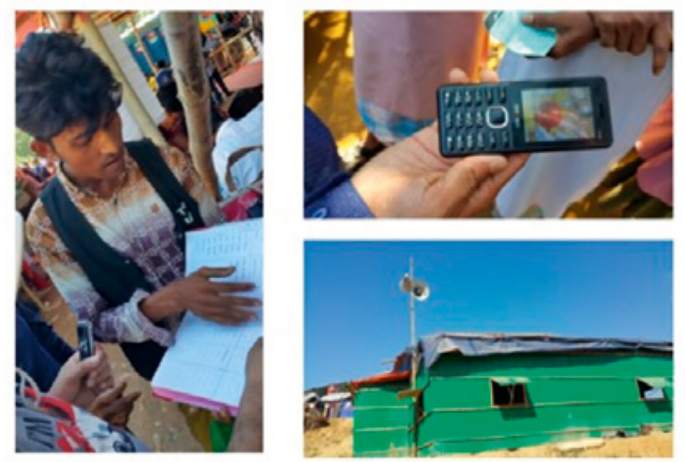

FIGURE 1

Common communication apparatuses in a Rohingya refugee camp ALL PHOTOS TAKEN BY HUSSAIN IN 2017

3 All photographs in this article are displayed with the permission of the respective copyright owners. 
The majhis depend heavily on digital means, especially mobile phones, in working with the community, and the absence of reliable internet and mobile services makes their day-to-day work difficult and costly, as pointed out by two of our interviewees:

Our Burmese sIm hardly works in Bangladesh. So, we need local sIM cards to talk. Legally, we are not allowed to have access to Bangladeshi mobile services, but thanks to the help of local people, we now have our Bangladeshi phones and talk freely. (a thirty-year-old male majhi)

We do not get network inside the camp after 4 PM. We also have to pay more in the local shops to talk using Bangladeshi sIMs. Such situations adversely affect our ability to help the community. (a head majhi)

\subsubsection{Imams and Other Religious Leaders}

In Myanmar, the Rohingya are systemically discriminated against for their religious identity - a collective reference to their Islamic, rather than Buddhist, traditions and practices. In this context, the influence of clergy over the Rohingya population is significant. Our initial observation, however, was that their influence diminished in the aftermath of the 2017 exodus of Rohingyas to Bangladesh. The unfamiliar administrative mechanisms of the host country and donor agencies, combined with the rise of majhis as community leaders, somewhat weakened the socio-political influence of imams and other Muslim religious leaders.

Nevertheless, the research team subsequently observed that the Rohingya clergy began to regain their power and status in the community. The camps have a large and well-established network of makeshift mosques and madrassahs (Islamic religious schools). According to a report by ввс Media Action (2018), as well as our first-hand observations in the field over the years, mosques are among the most trusted sources of information, according to camp dwellers.

Furthermore, as we elaborate below, madrassahs provide stateless Rohingyas with structured learning content and local support networks. Our focus group discussions with Rohingya imams (see Figure 2) highlighted that an increasing number of refugee families prefer that their children go to madrassahs for religious education, instead of an educational programme that humanitarian agencies produced in haste for a new mass of refugees in Bangladesh.

We also found that the clergy explicitly endorse the increasing use of digital technologies by young Rohingya men, as exemplified in an interview excerpted below. This sharply contrasts with their long-standing opposition to access to 


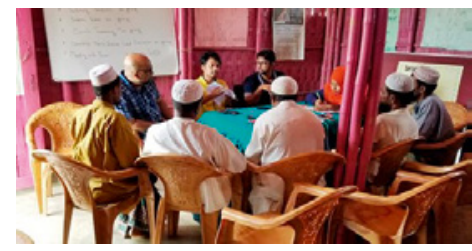

FIGURE 2

A focus group discussion with Rohingya imams PHOTOGRAPHED BY AN ANONYMOUS ROHINGYA VOLUNTEER IN 2019

education or digital technologies by Rohingya women, a point we return to later in the article.

Kids are our future. They need to educate themselves about technology. They should help our nation and religion to grow further. (a thirty-fiveyear-old male imam)

\subsubsection{Political Leaders}

We also observed the rise of new political leaders, who have slowly yet steadily gained acceptance among the refugees in Bangladesh. These new political leaders promote the vision of a Rohingya nation. Their popularity is largely attributed to their inclusive agenda, distinguishable from the conservative views of the clergy and patriarchy. Some of them are also well connected with, and supported by, Rohingya diasporas in other parts of the world.

Despite their popularity among the broad refugee population, they have faced numerous challenges in mobilizing people, both offline and online. The restrictions put in place by the Bangladesh government prohibit Rohingya refugees from venturing outside their designated camp areas or congregating with refugees from other camps. On top of that, the government's ban on mobile phone access in the camps, in conjunction with the lack of reliable internet connections, makes it extremely difficult for those emerging political leaders to communicate with the rest of the community and organize any group activities.

\subsection{A Renewed Thirst for Education}

For decades, the Myanmar authorities have maintained tight restrictions on Rohingyas' access to education. This discriminatory policy has resulted in a population with extremely low literacy rates and limited agency to fight for their rights politically. According to the Inter-Sector Coordination Group (ISCG), the central coordinating body for humanitarian organizations serving Rohingya refugees in Bangladesh (2017, cited in Shohel 2020), the refugees' basic literacy rate hovers between 5 percent and 27 percent. The situation is worse among 


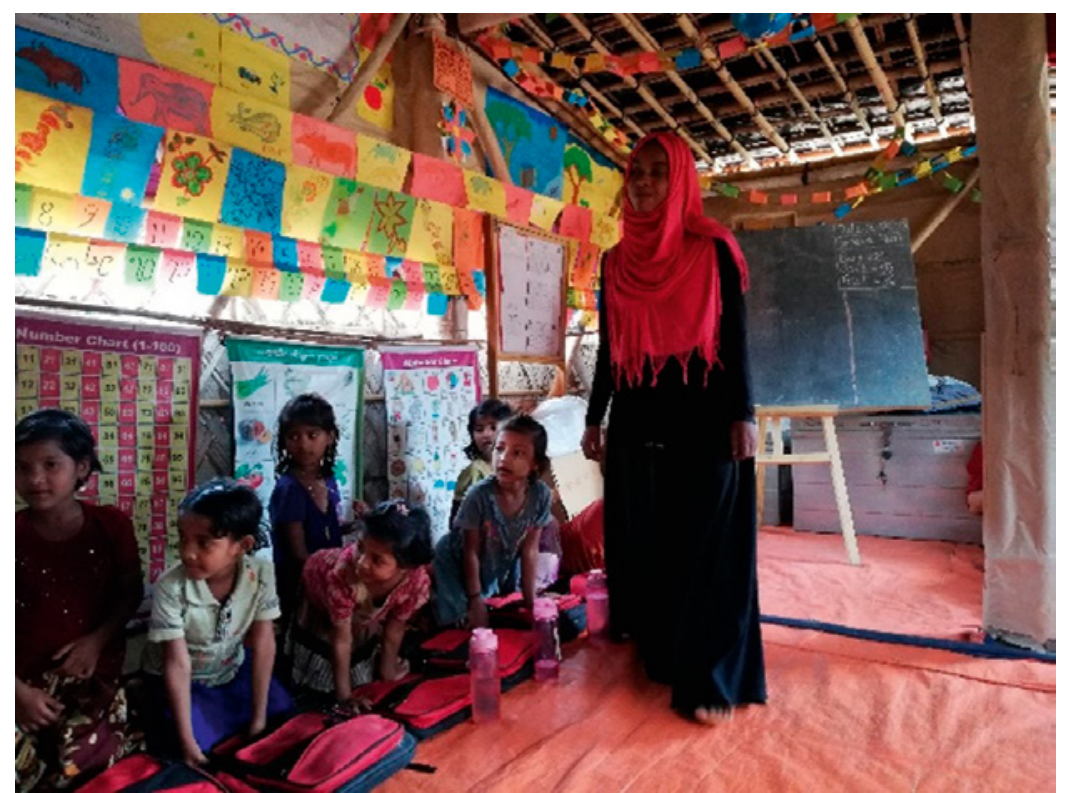

FIGURE 3 Inside a classroom for refugees, where a teacher from the local host community is leading an interactive learning session PHOTO BY ABDULLAH IN 2018

the younger generations, who constitute the majority of the refugee population. The United Nations Office for the Coordination of Humanitarian Affairs (ОСнA) (2018) reported that over 530,ooo children, age three to seventeen, are in immediate need of education in emergency (EiE) services.

OCHA (2018) also found that among primary-school-age children, that is, age six to fourteen, around 57 percent of girls and 6o percent of boys have attended makeshift learning centres with no regular curriculum since their arrival in Bangladesh. This absence of a structured education programme for Rohingya children has been a source of frustration for their parents, as encapsulated by one of our interviewees in the following statement:

Our children, who studied in school in Myanmar, have forgotten everything here because they do not have those books or resources to learn those topics again (a thirty-year-old female homemaker).

\subsection{Rohingya Women's Negotiation of Agency}

Rohingya women face two challenges: being refugees and being women in an Islamic culture. Traditionally, they are discouraged from organizing themselves and have limited movement outside their homes. Although when they were in 
Myanmar these were certainly the norms, it is hard to maintain those norms in refugee camps, where their living arrangements are not necessarily according to family units. Moreover, Rohingya women who wish to receive relief supplies have no option but to venture outside their makeshift camp dwellings.

Despite these new circumstances, Rohingya women have remained at the margins of key development initiatives. When it comes to basic health care, vaccination, and family planning, they do not have full liberty and, instead, must make choices based on the opinions of their spouses, the male heads of their families, or their religious leaders. They are also heavily discouraged from receiving an education.

Throughout our fieldwork, we asked our male participants about their perceptions of women using digital technologies, and all of them expressed opposition to the idea. Interestingly, an imam even offered a definition of an acceptable limit to Rohingya women's use of technology: 'Women can talk over the phone, but they should not be allowed to use the phone'. Others added that it might be acceptable for married women to have access to phones, but all the male participants said that 'young and unmarried women should never use mobile phones or the internet'.

Female participants generally prefer voice calls to app-based communication, and, irrespective of their education or family background, they rely heavily on male family members to access audio-visual content via smartphones.

We watch the videos of songs, dramas, and movies that our sons share with us. We don't download those or buy such things from others (a fortyyear-old Rohingya woman).

That said, we found that Rohingya women started to push back against these socially imposed restrictions and that their access to mobile phones, albeit limited, played an important role in this change. Over the span of our threeyear project, we conducted a series of women-only focus group discussions, including one in July 2019 with Rohingya women working for local NGOs as community development workers (left-hand-side image in Figure 4) and one in December 2018 with those who were predominantly homemakers (right-hand-side image in Figure 4). We found that an increasing number of Rohingya women now work with the NGOS and humanitarian agencies serving inside the camp areas. A majority of these women use mobile phones - both smartphones and feature phones - in their work, and they show a good understanding of the potential and risk of using the internet and mobile phones. For example, a thirty-six-year-old Rohingya woman said: 'The internet to me is the ability to catch the people who harass my girls over the phone all the time'. 


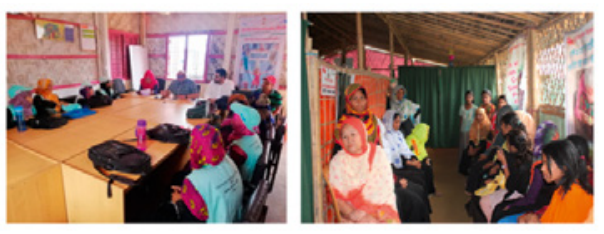

FIGURE 4

Focus group discussions with Rohingya women

LEFT PHOTO BY DHAR IN 2019; RIGHT

PHOTO BY NAUMI IN 2018

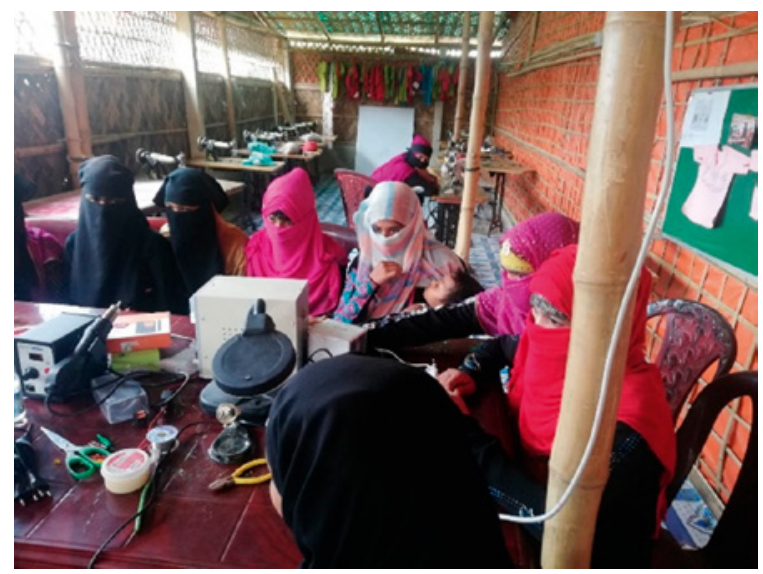

FIgURE 5 A mobile phone repair class for Rohingya women

PHOTO BY ABDULLAH IN 2018

For many Rohingya women, simply recharging a phone can be a major challenge, especially during the monsoon season, as described by a twentyeight-year-old female participant:

When it rains, solar lamps don't work properly. Those lamps then cannot be used to charge our phones. We have to send our phones to the mobile charging shops in the bazaar to get them charged. My son does that for me.

One of the most notable developments during our fieldwork was that female refugees requested training on how to repair mobile phones. This training was not part of any NGO's initial agenda, but at the insistence of Rohingya women, mainly younger women, UN Women, together with the local NGO Young Power in Social Action (YPSA), arranged a series of classes for them to learn this skill. The photograph in Figure 5 was taken in a UN Women-sponsored safe space for women, where classes on sewing and handicrafts were offered (captured in the background). However, these young women took the initiative to organize 
training on repairing mobile phones, as they identified this skill as crucial in maintaining their phones and potentially generating income.

\subsection{Mobile Phones for Social, Religious, and Political Organizing}

We found that Rohingya community leaders have embraced digital technologies to make their work more efficient, even with the on-and-off internet shutdowns by the Bangladesh government. The ban on purchases of Bangladeshi sims does not seem to have deterred them from using mobile phones, either. Most of the majhis with whom we spoke had smartphones and used messaging applications such as WhatsApp and Imo to communicate with their assigned communities and among their peers.

Ironically, mobile phones are also the main method of communication between the majhis and the Bangladesh government, even though it prohibits Rohingya refugees from using mobile phones in the country. This contradiction highlights a mismatch between refugee policy and practice. One of our participants, a nineteen-year-old Rohingya man, voiced his frustration:

I know I am using an illegal sIm card, and I know I paid a lot more to a local vendor to get it. But what should I do? I need to be in touch with my family members, who are located in other refugee camps or outside Bangladesh.

In this monetary context, we found an informal economy at work, in which Rohingya refugees do odd jobs under the radar, trade or barter relief supplies, and sell any valuables that they may have carried with them when they fled.

Our findings also indicate that YouTube is very popular among the majhis. A forty-five-year-old senior majhi stated:

Our young people and the mobile repair shops download 'new news' from YouTube every three to four days. That helps us to stay updated on what is going on outside our camps. Some of us also use Facebook. The use of Facebook is a good thing. People can know about our situation quickly through Facebook.

As discussed earlier, religious leaders are strongly opposed to Rohingya women's use of digital technologies. However, they are generally amenable to the practice of using mobile phones to download and watch religious videos and sermons. Many of them believe that this practice provides young Rohingyas with an opportunity to learn more about their religion. Our field research shows that at mobile repair and recharge shops, the most popularly shared 
content, via memory cards, is videos of Islamic sermons. A forty-three-year-old imam described this trend as follows:

The internet helps us to be close to our ummah (world of Islam). It further helps to share religious ideas easily and quickly. Yes, there are some bad side effects, but using the internet, we can do God's work!

We also note that, other than majhis and imams, political leaders in the refugee camps welcome information and communication technologies (ICT s). The research team met with one of the political leaders (who wishes to remain anonymous) who discussed in detail how he mobilizes his followers and workforce, using a mix of online and offline methods for communication. He successfully draws upon social networks around him, both physical and digital, to stay connected with his community. Online, he actively engages with different social media platforms, mainly WhatsApp and Facebook. He and his team also have produced short audio and video presentations to address issues that affect daily life in the camps.

Just after our field trips in the summer of 2019, the group that he led (and with whom we interacted) was instrumental in organizing one of the biggest Rohingya rallies in history. The rally was to commemorate the second anniversary of the Burmese military crackdown that triggered the latest exodus of Rohingyas from Myanmar to Bangladesh in 2017. To make it happen, his group took a multi-pronged approach involving Facebook, WhatsApp, Imo, and inperson contact.

\subsection{Mobile Phone Repair and Recharge Shops and a New Generation of Refugee Entrepreneurs}

We have identified not just operational, religious, and political leaders among refugees but also a new generation of 'entrepreneurial leaders'. They have risen in status as they have successfully responded to the fundamental need of fellow refugees for relevant information and effective communication. They assume a 'bridging' role, bypassing the legal restrictions and providing digital resources for those with less agency and lower digital literacy.

Over the course of our fieldwork, we surveyed twenty mobile repair and recharge shops in different parts of the camp areas. A typical mobile phone shop offers a combination of three services: mobile phone repair services (for both smartphones and feature phones), mobile phone recharging services, and transferring audio-visual content from the shop's devices to the client's SIM card or phone. 

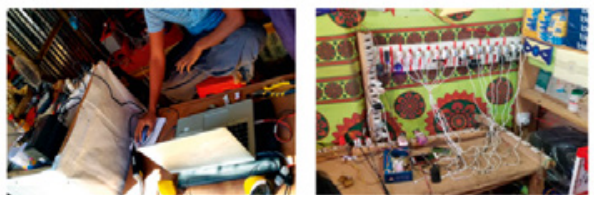

FIGURE 6

Mobile repair and recharge shops inside the camp areas

BOTH PHOTOS BY HUSSAIN: THE

LEFT-HAND PHOTO TAKEN IN 2017 AND

THE RIGHT-HAND PHOTO TAKEN IN 2019

In addition, bigger shops sell refurbished mobile phones, chargers, sIM cards, earphones, various mobile phone accessories, small and medium-size solar panels, and solar lamps. Some shops also offer other services, such as photocopying, scanning, printing (including printing wedding cards), and laminating.

A majority of the shopkeepers who offer mobile phone repair service had prior technical training in Myanmar, and some of them received assistance in setting up their businesses from local experts. These shops, illustrated in Figure 6, are incredibly popular among young Rohingya men, who frequent these establishments as their social clubs. The left-hand image in Figure 6 (taken in November 2017) shows a mobile repair shop that also doubles as a digital content shop. The shop in the right-hand image (from December 2019) provides printing and mobile recharging services. These shops are run by refugees, with most of the initial investments by Rohingyas who went to Bangladesh before 2017 and have since naturalized there.

Mobile phone recharging services are particularly popular. Due to the lack of electricity in the areas, recharging a smartphone is a massive challenge. Hence, mobile phone recharging services attract a steady stream of customers, mainly Rohingya men in their twenties. As their digital devices require regular recharging, these shops have become their go-to place to hang out and exchange information. A comparable phenomenon was observed in other parts of Asia in earlier periods in the popularization of internet technology. For example, Lim (2018) recounts that between the mid-199os and mid-20oos the internet became commercially available in Indonesian cities at local-style internet cafés (warnet), where people had snacks, lingered, and exchanged information and gossip.

The most innovative service provided by mobile phone repair and recharge shops in the Rohingya refugee camps is arguably the content transfer service, which we call a 'parallel internet'. As mentioned earlier, the restrictions on Rohingyas' ownership of mobile phones and access to the internet created huge demand for good-quality information and entertainment among the camp dwellers. It is also noteworthy that the Rohingya are a predominantly 
oral society. The fact that they have no official written language, combined with the fact that they were explicitly discouraged from learning other languages in Myanmar, explains the lack of newspapers, books, and other literary materials in circulation in the camps. Against this backdrop, culturally appropriate audio-visual content gained importance for the community in their new environment.

However, we observed that the humanitarian agencies and other NGOS working for the betterment of Rohingya refugees prioritized the supply of food, shelter, and medical assistance. Providing digital content of news and entertainment, customized for Rohingya consumption, has not been part of the mission. This gap was quickly and organically filled by mobile phone shops. Each shop is typically equipped with at least one laptop and numerous hard drives loaded with a wide range of audio-visual content. Due to generally poor connections, shop owners download and save in advance short audio/video clips with Rohingya-related news, reports, and features on their devices. The clips are then transferred to customers' mobile phones for a small fee. These shops are effectively the suppliers of up-to-date and relevant content for the community. This resonates with a growing body of literature documenting entrepreneurial efforts by refugees despite their resource-constrained circumstances, exemplified in the studies by Heilbrunn (2019) and Kwong et al. (2019). Such efforts are aptly referred to as 'bricolage' (i.e. making do with whatever is at hand) or, more broadly, 'constraint-based innovations' (Agarwal et al. 2017).

\section{Conclusion and Lessons Learnt}

Based on ethnographic fieldwork conducted in Rohingya refugee camps in Bangladesh between 2017 and 2019, this article offers a holistic and contextualized account of Rohingyas' day-to-day life in the camps, in particular how they use digital resources despite their limited access.

Our findings highlight the technical and institutional barriers that Rohingya refugees face in using digital devices and platforms, including the host government's on-and-off ban on mobile phone services and sim card sale in the camps, which consequently hinders the already vulnerable community from obtaining essential information and humanitarian relief.

That said, we found that Rohingya refugees demonstrate resilience and creativity in navigating these inhibiting environments - 'digital borderscapes' and making the best of whatever means are available, or 'digital bricolage'. The 
community organizes itself around various types of new leader figures, namely majhis (operational leaders, who bridge between the camp dwellers and the Bangladesh government and international humanitarian agencies), imams (religious leaders, who provide Islamic guidance for the community and a much-needed education programme for children), and political leaders (who promote the vision of a Rohingya nation, based on more inclusive and progressive agenda than the conservative views of the clergy and patriarchy).

On the technological front, because of the unstable supply of electricity and restricted access to telecommunication services in the camp areas, Rohingyas, particularly those in their twenties, frequent mobile phone shops to have their phones recharged, to purchase news and entertainment content (usually downloaded from YouTube), and to hang out in general. In other words, those shops play a crucial role in addressing the refugee community's digital needs, filling the gap left by the refugee support mechanism currently in place.

Rohingya women continue to face discrimination on two fronts: as refugees and as Muslim women. The Muslim traditional norms place them under the direction of the male members of their families and discourage them from obtaining an education and using digital technologies. However, it is now hard to maintain these norms in the camps, where women have no option but to venture outside their homes on their own or to take a job. Female refugees leverage this new environment to pursue self-development, especially in digital skills.

Our study of Rohingya refugees' prolonged experiences of liminality offers three recommendations for policy makers and humanitarian NGOS, who can positively influence the new life of refugees and other forcibly displaced people. First, access to digital information and communication technologies is not a luxury and needs to be ensured as part of fundamental rights. This study is certainly not the first to arrive at that conclusion, but it provides further evidence that it is important to make explicit efforts at the policy level. Otherwise, people on the move or caught between the boundaries of nation-states are often forgotten in the discussion of digital rights.

A second and related point is that a user-centred approach is crucial in meeting digital needs. What Rohingya refugees in Bangladesh actually need on the ground is not taken into account when policy decisions are made, compounding their precarious and vulnerable situation.

Third, it is important to push back against the stereotypical, homogeneous representation of refugees and, instead, to acknowledge their constraint-based innovations. Rohingya women in particular have demonstrated the initiative and willingness to adapt and make concrete improvement in their new lives. 


\section{References}

Agarwal, Nivedita, Grottke, Michael, Mishra, Shefali \& Brem, Alexander (2017), 'A Systematic Literature Review of Constraint-Based Innovations: State of the Art and Future Perspectives'. IEEE Transactions on Engineering Management, 64(1), 3-15.

Al Jazeera (2018, 18 April), 'Who Are the Rohingya?' Retrieved 24 September 2020 from https://www.aljazeera.com/features/2018/o4/18/who-are-the-rohingya/.

Amnesty International (2017), “Caged Without a Roof": Apartheid in Myanmar's Rakhine State'. Retrieved 24 September 2020 from https://www.amnesty.org.uk/ files/CagedwithoutaRoof-ApartheidMyanmar-AIreport.pdf.

Appadurai, Arjun (1990), 'Disjuncture and Difference in the Global Cultural Economy'. Theory, Culture \& Society, 7(2-3), 295-310.

Aricat, Rajiv George (2015), 'Mobile/Social Media Use for Political Purposes Among Migrant Laborers in Singapore'. Journal of Information Technology \& Politics, 12(1), $18-36$.

в вс Media Action (2018), 'How Effective Is Communication in the Rohingya Refugee Response?' Retrieved 28 September 2020 from http://downloads.bbc.co.uk/media action/pdf/research/rohingya-research-report.pdf.

Cassidy, Kathryn, Yuval-Davis, Nira \& Wemyss, Georgie (2018), 'Debordering and Everyday (Re)Bordering in and of Dover: Post-Borderland Borderscapes'. Political Geography, 66, 171-179.

Dell'Agnese, Elena \& Szary, Anne-Laure Amilhat (2015), 'Borderscapes: From Border Landscapes to Border Aesthetics'. Geopolitics, 2O(1), 4-13.

Gillespie, Marie, Osseiran, Souad \& Cheesman, Margie (2018), 'Syrian Refugees and the Digital Passage to Europe: Smartphone Infrastructures and Affordances'. Social Media + Society, 4(1), 2056305118764440.

Harbers, Arjan (2003), 'Borderscapes, The Influence of National Borders on European Spatial Planning'. In: Broesi, Robert (Ed.), Euroscapes. Amsterdam: Must Publishers, 143-166.

Heilbrunn, Sibylle (2019), 'Against All Odds: Refugees Bricoleuring in the Void'. International Journal of Entrepreneurial Behavior \& Research, 25(5), 1045-1064.

Hussain, Faheem (2018, 14 June), 'Digital Access Isn't a Luxury for Refugees: It's a Necessity'. Slate. Retrieved 24 September 2020 from https://slate.com/techno $\log / 2018 / 06 /$ digital-access-isnt-a-luxury-for-refugees-its-a-necessity.html.

Krichker, Dina (2019), 'Making Sense of Borderscapes: Space, Imagination and Experience'. Geopolitics [published online first].

Kwong, Caleb C.Y., Cheung, Cherry W.M., Manzoor, Humera \& Rashid, Mehboob Ur (2019), 'Entrepreneurship Through Bricolage: A Study of Displaced Entrepreneurs at Times of War and Conflict'. Entrepreneurship \& Regional Development, 31(5-6), $435^{-455}$. 
Lim, Merlyna (2018), 'Dis/Connection: The Co-Evolution of Sociocultural and Material Infrastructures of the Internet in Indonesia'. Indonesia, 105, 155

Mann, Monique \& Daly, Angela (2020), 'Geopolitics, Jurisdiction and Surveillance'. Internet Policy Review, 9(3) [published online first].

Mohdin, Aamna (2017, 3 October), 'A Brief History of the Word "Rohingya" at the Heart of a Humanitarian Crisis'. Quartz. Retrieved 24 September 2020 from https://qz.com/1092313/a-brief-history-of-the-word-rohingya-at-the-heart-of-a -humanitarian-crisis/.

OCHA (2018, 1 June), 'Joint Education Needs Assessment: Rohingya Refugee in Cox's Bazar, June 2018'. Retrieved 1 October 2020 from https://www.humanitarian response.info/sites/www.humanitarianresponse.info/files/documents/files/cxb jena_assessment_report-1806o7.pdf.

O'Malley, James (2015, 7 September), 'Surprised That Syrian Refugees Have Smartphones? Sorry to Break This to You, But You're an Idiot'. The Independent. Retrieved 24 September 2020 from https://www.independent.co.uk/voices/ comment/surprised-syrian-refugees-have-smartphones-well-sorry-break-you-you -re-idiot-10489719.html.

Parashar, Archana \& Alam, Jobair (2019), 'The National Laws of Myanmar: Making of Statelessness for the Rohingya'. International Migration, 57(1), 94-108.

Perera, Suvendrini (2007), 'A Pacific Zone? (In)Security, Sovereignty, and Stories of the Pacific Borderscape'. In: Rajaram, Prem Kumar \& Grundy-Warr, Carl (Eds.), Borderscapes: Hidden Geographies and Politics at Territory's Edge. Minneapolis: University of Minnesota Press, pp. 201-230.

Privacy International (2020), '10 Threats to Migrants and Refugees'. Retrieved 15 October 2020 from http://privacyinternational.org/long-read/400o/10-threats -migrants-and-refugees/.

Rajaram, Prem Kumar \& Grundy-Warr, Carl (2007), Borderscapes: Hidden Geographies and Politics at Territory's Edge. Minneapolis: University of Minnesota Press.

Reventlow, Nani Jansen \& McCully, Jonathan (2019, 27 February), 'Digital Rights Are *All* Human Rights, Not Just Civil and Political'. Berkman Klein Centre for Internet \& Society. Retrieved 24 September 2020 from https://medium.com/berkman-klein -center/digital-rights-are-all-human-rights-not-just-civil-and-political-dafifi713f7a/.

Rüland, Anchalee (2017), 'Myanmar's Rohingya Problem in Context'. Ispsw Strategy Series: Focus on Defense and International Security 485.

Schimanski, Johan \& Wolfe, Stephen F. (Eds.) (2017), Border Aesthetics: Concepts and Intersections. Oxford: Berghahn Books.

Seekins, Donald M. (2017), Historical Dictionary of Burma (Myanmar) (2nd ed). London: Rowman \& Littlefield.

Shohel, M. Mahruf C. (2020), 'Education in Emergencies: Challenges of Providing Education for Rohingya Children Living in Refugee Camps in Bangladesh'. Education Inquiry [published online first]. 
UNHCR (2019), 'Rohingya Emergency'. Retrieved 24 September 2020 from https://www .unhcr.org/rohingya-emergency.html.

UNHCR (2020), 'Internet Governance in Displacement'. Retrieved 6 October 2020 from https://www.unhcr.org/innovation/wp-content/uploads/2020/o4/Internet-Gover nance-in-Displacement_WEBo42O2O.pdf.

Wall, Melissa, Campbell, Madeline Otis \& Janbek, Dana (2017), 'Syrian Refugees and Information Precarity'. New Media \& Society, 19(2), 240-254.

Zaborowski, Rafal \& Georgiou, Myria (2016, 17 November), 'Refugee "Crisis"? Try "Crisis in the European Press"'. Opendemocracy. Retrieved 24 September 2020 from https://www.opendemocracy.net/en/refugee-crisis-try-crisis-in-european-press/. 